\title{
Topical anti-inflammatory activity of Polygonum cuspidatum extract in the TPA model of mouse ear inflammation

\author{
Eve E Bralley ${ }^{1}$ Phillip Greenspan ${ }^{1}$, James L Hargrove*2, Louise Wicker ${ }^{3}$ and \\ Diane K Hartle ${ }^{1}$
}

Address: ${ }^{1}$ Department of Pharmaceutical and Biomedical Sciences, Nutraceutical Research Laboratories, University of Georgia, Athens, GA, USA, 2Department of Food and Nutrition, Nutraceutical Research Laboratories, University of Georgia, Athens, GA, USA and ${ }^{3}$ Department of Food Science and Technology, University of Georgia, Athens, GA, USA

Email: Eve E Bralley - bralleye@rx.uga.edu; Phillip Greenspan - greenspn@rx.uga.edu; James L Hargrove* - jhargrov@fcs.uga.edu; Louise Wicker - lwicker@uga.edu; Diane K Hartle - dhartle@rx.uga.edu

* Corresponding author

\author{
Published: 8 February 2008 \\ Received: 6 September 2007 \\ Journal of Inflammation 2008, 5: I doi: 10.1 |86/| 476-9255-5-I \\ Accepted: 8 February 2008 \\ This article is available from: http://www.journal-inflammation.com/content/5/I/I \\ (c) 2008 Bralley et al; licensee BioMed Central Ltd. \\ This is an Open Access article distributed under the terms of the Creative Commons Attribution License (http://creativecommons.org/licenses/by/2.0), \\ which permits unrestricted use, distribution, and reproduction in any medium, provided the original work is properly cited.
}

\begin{abstract}
Background: This study tested the ability of a characterized extract of Polygonum cuspidatum (PCE) to inhibit mouse ear inflammation in response to topical application of 12-0tetradecanoylphorbol-I3-acetate (TPA).

Methods: A 50\% (wt:vol) ethanolic solution of commercial 200:I PCE was applied to both ears of female Swiss mice $(n=8)$ at $0.075,0.15,0.3,1.25$ and $2.5 \mathrm{mg} /$ ear $30 \mathrm{~min}$ after TPA administration ( $2 \mu \mathrm{g} / \mathrm{ear})$. For comparison, 3 other groups were treated with TPA and either I) the vehicle $(50 \%$ ethanol) alone, 2$)$ indomethacin $(0.5 \mathrm{mg} / \mathrm{ear})$, or 3$)$ trans-resveratrol $(0.62 \mathrm{mg} /$ ear). Ear thickness was measured before TPA and at 4 and $24 \mathrm{~h}$ post-TPA administration to assess ear edema. Ear punch biopsies were collected at $24 \mathrm{~h}$ and weighed as a second index of edema. Myeloperoxidase activity was measured in each ear punch biopsy to assess neutrophil infiltration.
\end{abstract}

Results: PCE treatment at all doses significantly reduced ear edema compared to the TPA control. The PCE response was dose-dependent and $2.5 \mathrm{mg}$ PCE significantly inhibited all markers of inflammation to a greater extent than indomethacin $(0.5 \mathrm{mg})$. MPO activity was inhibited at PCE doses $\geq 1.25 \mathrm{mg} /$ ear. Trans-resveratrol inhibited inflammation at comparable doses.

Conclusion: PCE inhibits development of edema and neutrophil infiltration in the TPA-treated mouse ear model of topical inflammation.

\section{Background}

Polygonum cuspidatum Sieb et Zucc., commonly called Japanese knotweed or Mexican bamboo, is a member of the Polygonaceae family that is widely distributed in Asia and North America. Interest in Polygonum cuspidatum (PC) has increased owing to the high concentration of resveratrol and its glycosides in the root $[1,2]$. In traditional Chinese medicine, PC is called $H u$ Zhang and is used as an analgesic, antipyretic, diuretic, and an expectorant. Traditional uses include treatments for arthralgia, chronic bronchitis, jaundice, amenorrhea, and high blood pressure [3]. Several studies have evaluated the antioxidant capacity of Polygonum cuspidatum extract (PCE) [4,5], and anti-inflammatory activities such as inhibition of NF-kB have been 
reported [6-8]. At present, studies of PCE effects on classic symptoms of inflammation such as edema and neutrophil infiltration are lacking.

PCE is used as an ingredient in many nutraceutical product formulations because of its high concentration of trans-resveratrol, a polyphenolic trans-stilbene (3, 4'-5-trihydroxystilbene). Resveratrol and related phytochemicals produce antioxidant, cardioprotective, immunomodulatory, chemopreventive, anti-bacterial, anti-fungal, and anti-viral effects [9-14]. The concentration of resveratrol in sources such as grapes and red wine varies depending on environmental conditions [15]. Therefore, PCE is being used commercially as an additive to standardize resveratrol concentration in extracts of grape pomace (skins and seeds) that have low or variable natural concentrations $[16,17]$. Also, additive and synergistic effects have been noted for combinations of resveratrol and flavonoids such as quercetin and ellagic acid [18].

PCE has not been tested in the tetradecanoylphorbol acetate (TPA)-treated mouse ear model of inflammation. This model evaluates whether pharmaceutical agents or natural products may block the inflammatory response to topical TPA [19-21]. Because PCE is being used as an ingredient in cosmeceutical products that are applied to the skin and in nutraceutical products that are ingested, it is worthwhile to test PCE activity in this model. The skin and gastrointestinal mucosa are both subject to inflammation, but it is far easier to screen for anti-inflammatory effects on an accessible surface than on an internal epithelium. Therefore, the present study tested whether PCE has topical anti-inflammatory activities in the well-characterized TPA-induced mouse ear model of inflammation, edema, and PMN leukocyte infiltration [22,23]. Total phenolics and ferric reducing antioxidant power (FRAP values) were measured in the ethanolic PCE because both characteristics may reflect the degree of anti-inflammatory activity of the preparation. For example, Chung et. al. reported that edema formation in the TPA model may be regulated by $\mathrm{H}_{2} \mathrm{O}_{2}$ generation [24], as evidenced by antiinflammatory activity of several antioxidant compounds $[25,26]$.

\section{Materials and methods \\ Materials}

12-O-Tetradecanoylphorbol 13-acetate, hexadecyltrimethylammonium bromide, indomethacin (minimum 99\% TLC), 3,3',5,5'-tetramethylbenzidine dihydrochloride, $N$, N-dimethylformamide, trans-3,4',5-trihydroxystilbene (trans-resveratrol), Folin-Ciocalteu reagent, gallic acid, and $10 \mathrm{mM}$ 2,4,6-tripyridyl]-1,3,5-triazine (TPTZ) were all purchased from Sigma-Aldrich Chemical Co. (St. Louis, MO). Polygonum cuspidatum 200:1 powdered extract was purchased from Supplemental Health Formulations (Mayer, AZ).

\section{Preparation of ethanolic solution of Polygonum cuspidatum extract (PCE)}

PCE used in this study was a 200-fold concentrate prepared from PC root grown in China. Chemical analysis from Supplemental Health Formulations reported that the trans-resveratrol complex was at least $500 \mathrm{mg} / \mathrm{g}$ and emodin content was $<20 \mathrm{mg} / \mathrm{g}$. The 200:1 PC powder was dissolved in $50 \%$ ethanol ( 1 part PC to 9 parts ethanol) and stirred for $1 \mathrm{~h}$ at $23^{\circ} \mathrm{C}$. The mixture was centrifuged (1500 rpm for $10 \mathrm{~min}, 4^{\circ} \mathrm{C}$ ) and the supernatant was diluted for topical dose-response applications in this study. The majority of the powder was not soluble in $50 \%$ ethanol under these conditions.

\section{Chromatographic analysis of the Polygonum cuspidatum ethanolic solution}

The ethanolic extract was diluted 400-fold and subjected to HPLC analysis using an ESA (Chelmsford, MA) system consisting of a Model 582 Solvent Delivery Module, a Model 542 autosampler maintained at $6^{\circ} \mathrm{C}$ and a Model $5600 \mathrm{~A}$ CoulArray detector at $250 \mathrm{mV}$. The column was an MCM C18 (4.6 × 150 mm, 5-120 A) from MC Medical, Japan. Mobile phase A was $75 \mathrm{mM}$ citric acid, $25 \mathrm{mM}$ ammonium acetate and 10\% acetonitrile; Mobile phase B was similar to A but with $50 \%$ acetonitrile. The gradient was linear from 0-17 minutes from $10 \%$ A to $80 \%$ B. Flow rate was $1.0 \mathrm{ml} / \mathrm{min}$ and $20 \mu \mathrm{l}$ of sample was injected. Resveratrol eluted between 16.2 and 16.8 minutes as judged by a standard obtained from Sigma-Aldrich (St. Louis, $\mathrm{MO})$.

\section{Measurement of total phenolic compounds}

Total phenolic acid content of each extract was measured by the method of Slinkard and Singleton [27] with minor modifications. Triplicate samples of a 1:10 extract (wt/ vol) $(20 \mu \mathrm{L})$ were added to $1.58 \mathrm{~mL}$ of distilled water in 3 $\mathrm{mL}$ polystyrene cuvettes. $100 \mu \mathrm{L}$ of Folin-Ciocalteu reagent was added and the sample was mixed well. Within 10 minutes, $300 \mu \mathrm{L}$ of sodium carbonate solution (200 g $\mathrm{Na}_{2} \mathrm{CO}_{3}$ in $1 \mathrm{~L}$ distilled water) was added. Solutions were incubated for $2 \mathrm{~h}$ at room temperature. Absorbance was measured at $765 \mathrm{~nm}$. Total phenolic acid concentration was calculated from a gallic acid standard curve (0-500 $\mathrm{mg} / \mathrm{L}$ ) and expressed as gallic acid equivalents per gram 200:1 PCE powder.

\section{Measurement of FRAP values (Ferric Reducing Antioxidant Power)}

The antioxidant activity of a 1:10 (wt/vol) extraction was determined in triplicate by the FRAP method [28]. $10 \mu \mathrm{L}$ of the sample or standard, $30 \mu \mathrm{L}$ of distilled water and 300 $\mu \mathrm{L}$ of FRAP reagent were mixed. FRAP reagent was made 
by mixing $25 \mathrm{~mL}$ acetate buffer ( $300 \mathrm{mM}, \mathrm{pH} 3.6), 2.5 \mathrm{~mL}$ of $10 \mathrm{mM}$ TPTZ solution dissolved in $40 \mathrm{mM} \mathrm{HCl}$, and 2.5 $\mathrm{mL}$ of $20 \mathrm{mM}$ ferric chloride solution. The solutions were incubated at $37^{\circ} \mathrm{C}$ for six minutes then $340 \mu \mathrm{L}$ of distilled water was added. The absorbance of the sample or standards was read immediately at $593 \mathrm{~nm}$. FRAP value was calculated from a standard curve of ferrous sulfate $(0-1$ $\mathrm{mmol} / \mathrm{L}$ ) and the antioxidant power of the PCE was expressed as mmol ferrous sulfate equivalents/100 g dry weight of the 200:1 PCE powder.

\section{Animals}

All animal experiments were approved by the Institutional Animal Care and Use Committee (IACUC) at the University of Georgia and conducted according to IACUC guidelines. The sample size of 8 animals for each test group was justified on the basis of a pilot experiment showing that the sample standard deviation (s) for measurements of ear edema was about $5 \%$ of the measured value and the average expected difference (d) between TPA treated ears and PCE-treated ears was about $0.2 \mathrm{~mm}$. Assuming that $\alpha=0.05$ and $1-\beta=0.9$, the formula used was $\mathrm{n}$ (sample size $)=1+21^{*}(\mathrm{~s} / \mathrm{d})^{2}[29]$. The formula gave 6.25 , which was increased to 8 in case of unexpected experimental problems. Female Swiss Webster mice (Harlan Laboratories, Indianapolis, IN) weighing 22-25 g were housed in groups of 4 in large shoebox cages. All groups were fed a standard rodent diet (TestDiet ${ }^{\circledast}$ 570B, Purina Mills, St. Louis, MO) ad libitum with free access to water. Animals were in the fed condition throughout the experiment. Photoperiods equaled $12 \mathrm{~h}$ of light and $12 \mathrm{~h}$ of darkness daily, with the environmental temperature maintained at $21^{\circ} \mathrm{C}$.

\section{TPA-induced mouse ear edema}

Edema was induced in both ears of each mouse by the topical application of $2 \mu \mathrm{g}$ TPA dissolved in $20 \mu \mathrm{L}$ of acetone to both the inner and outer ear surfaces. Thirty minutes after the application of TPA, the inner and outer surface of each ear was treated ( $10 \mu \mathrm{L}$ to each side) with $50 \%$ ethanolic solutions of PCE in doses of $0.075,0.15$, $0.3,1.25$ and $2.5 \mathrm{mg}$ PCE/ear ( $\mathrm{n}=8$ at each dosage). Comparisons included equal volumes of $50 \%$ ethanol (vehicle control), indomethacin ( $0.5 \mathrm{mg} /$ ear dissolved in $50 \%$ ethanol as an anti-inflammatory drug standard), or a $50 \%$ ethanol solution of trans-3, 5, 4'-trihydroxystilbene (resveratrol, $0.6 \mathrm{mg} /$ ear). The thickness of each ear was measured using a micrometer (Mitutoyo Series IP65, Mitutoyo America, Aurora, IL) before and at $4 \mathrm{~h}$ and $24 \mathrm{~h}$ after TPA administration. The micrometer was applied near the top of the ear distal to the cartilaginous ridges. At $24 \mathrm{~h}$ each animal was sacrificed with $\mathrm{CO}_{2}$ inhalation by the IACUC approved protocol. Ear punch biopsies (6 $\mathrm{mm}$ diameter hole punch) were taken immediately, weighed, frozen and stored at $-80^{\circ} \mathrm{C}$. A single investigator performed all ear measurements and biopsies in order to standardize the procedure and reduce experimental error.

\section{Myeloperoxidase assay}

Tissue MPO (MPO, E.C. 1.11.1.7) activity was measured in biopsies taken from both ears $24 \mathrm{~h}$ after TPA administration using a method by Suzuki et. al. [30] and modified by De Young et. al. [31]. Each mouse ear biopsy was placed in $0.75 \mathrm{~mL}$ of $80 \mathrm{mM}$ phosphate-buffered saline (PBS) $\mathrm{pH} 5.4$ containing $0.5 \%$ hexadecyltrimethylammonium bromide (HTAB). Each sample was homogenized for $45 \mathrm{~s}$ at $4^{\circ} \mathrm{C}$ with a small sample laboratory Tissue Tearor Homogenizer Model 985-370 (Biospec Products, Bartlesville, OK). The homogenate was transferred quantitatively to a microcentrifuge tube with an additional $0.75 \mathrm{~mL}$ HTAB in PBS. The $1.5 \mathrm{~mL}$ sample was centrifuged at $12,000 \times \mathrm{g}$ for $15 \mathrm{~min}$, maintained at $4{ }^{\circ} \mathrm{C}$. Triplicate $30 \mu \mathrm{L}$ samples of the resulting supernatant were added to 96-well microtiter plate wells. For the MPO assay, $200 \mu \mathrm{L}$ of a mixture containing $100 \mu \mathrm{L}$ of $80 \mathrm{mM}$ PBS (pH 5.4), $85 \mu \mathrm{L}$ of $0.22 \mathrm{M}$ PBS (pH 5.4), and $15 \mu \mathrm{L}$ of $0.017 \%$ hydrogen peroxide were added to each well. 20 $\mu \mathrm{L}$ of $18.4 \mathrm{mM}$ tetramethylbenzidine $\mathrm{HCl}$ in $8 \%$ aqueous dimethylformamide was added to start the reaction. Microtiter plates were incubated at $37^{\circ} \mathrm{C}$ for $3 \mathrm{~min}$, and then placed on ice. The reaction was stopped with the addition of $30 \mu \mathrm{L}$ of $1.46 \mathrm{M}$ sodium acetate, $\mathrm{pH}$ 3.0. MPO enzyme activity was assessed colorimetrically using a BioTek Microplate Reader (Winooski, VT) at an absorbance wavelength of $630 \mathrm{~nm}$. MPO activity was expressed as optical density (OD)/biopsy.

\section{Statistical analysis}

Data are expressed as the mean \pm standard error of the mean (SEM). Statistical evaluations used t-tests and oneway analysis of variance (ANOVA) with post-hoc tests for significance of differences by the Student-Newman-Keuls Method. Statistical significance was considered at $\mathrm{p}<$ 0.05 .

\section{Results \\ Total phenolics and FRAP values in PCE}

A $50 \%$ ethanolic extract $(1: 10 \mathrm{wt} / \mathrm{vol})$ of the 200:1 PCE yielded $188 \mathrm{mg}$ of total phenolics (gallic acid equivalents) per gram of PCE. Antioxidant power based on the FRAP assay was $85 \mathrm{mmol}$ ferrous sulfate equivalents/100 g dry weight of PCE. Most of the solids in the commercial extract were not soluble in $50 \%$ ethanol. The dry weight of the ethanol-insoluble pellet remaining after centrifugation of the extract from $1.0 \mathrm{~g}$ of powder equaled $0.76 \mathrm{~g}$, indicating that the majority was not soluble in $50 \%$ ethanol. Chromatography of the ethanol-soluble material as described in the Methods section showed only one major peak, which co-eluted with authentic trans-resveratrol (Figure 1). 


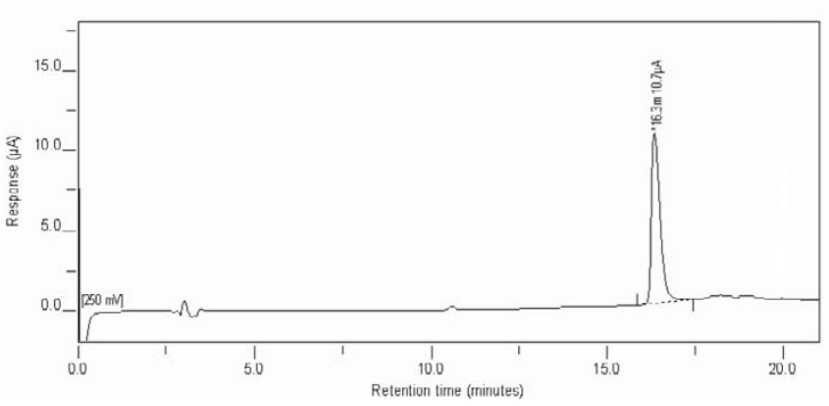

Figure I

Chromatogram of ethanol-soluble PCE fraction. A single major peak was observed in the chromatogram of the $50 \%$ ethanol soluble fraction of PCE that eluted at $16.3 \mathrm{~min}$ with the same retention time as authentic trans-resveratrol (not shown).

\section{Ear edema}

Ear edema was observed in all TPA-treated animals by $4 \mathrm{~h}$ and $24 \mathrm{~h}$ after treatment. In animals treated only with vehicle (50\% ethanol), initial ear thickness equaled 0.27 $\pm 0.01 \mathrm{~mm}$ (mean \pm SEM). Ear thickness increased to 0.42 $\pm 0.01 \mathrm{~mm}$ at $4 \mathrm{~h}$ and $0.46 \pm 0.02 \mathrm{~mm}$ by $24 \mathrm{~h}$ after TPA treatment. PCE-treated experimental groups showed significantly reduced ear edema compared to TPA treatment alone. Dosages tested included 0.075, 0.15, 0.3, 1.25 and $2.5 \mathrm{mg}$ PCE/ear ( $\mathrm{n}=8$ at each dosage). PCE at 2.5, 1.25, and $0.3 \mathrm{mg}$ per ear was as effective as indomethacin $(0.5$ $\mathrm{mg} /$ ear) in reducing edema (Figure 2). These treatments inhibited edema 61\%, 55\%, 52\%, and 65\% (Indo), respectively compared to TPA treated with vehicle controls. In comparison, $0.62 \mathrm{mg}$ of commercially purified trans-resveratrol inhibited edema by only 35\%. At 24 h, all experimental groups had significantly reduced ear edema compared to TPA alone except PCE at $0.075 \mathrm{mg}$ per ear and the trans-resveratrol-treated groups. PCE at 1.25, 0.3, and $0.15 \mathrm{mg}$ per ear inhibited edema as well as indomethacin (58\%, 36\%, 40\%, respectively, vs $45 \%$ for indomethacin. PCE applied at $2.5 \mathrm{mg}$ per ear was significantly more effective than indomethacin in reducing edema with a $73 \%$ reduction compared to the TPA treated vehicle control.

Edema was also indicated by changes in ear punch masses at $24 \mathrm{~h}$, and the treatment effects were similar to the changes in ear thickness shown in Figure 2. Typical masses of ear punch biopsies at $24 \mathrm{~h}$ were $9.1 \pm 0.3 \mathrm{mg}$ in vehicletreated controls compared to $17.5 \pm 0.7 \mathrm{mg}$ in TPA-treated animals. Ear punch biopsy weights were significantly lower in all PCE groups compared to the TPA-treated control group (data not shown). For example, $2.5 \mathrm{mg}$ of PCE reduced the change in ear mass to $1.3 \pm 0.25 \mathrm{mg}$ (an $80 \%$ reduction), which was significantly greater than the reduction by $0.5 \mathrm{mg}$ of indomethacin to $5.36 \pm 0.39 \mathrm{mg}(36 \%$

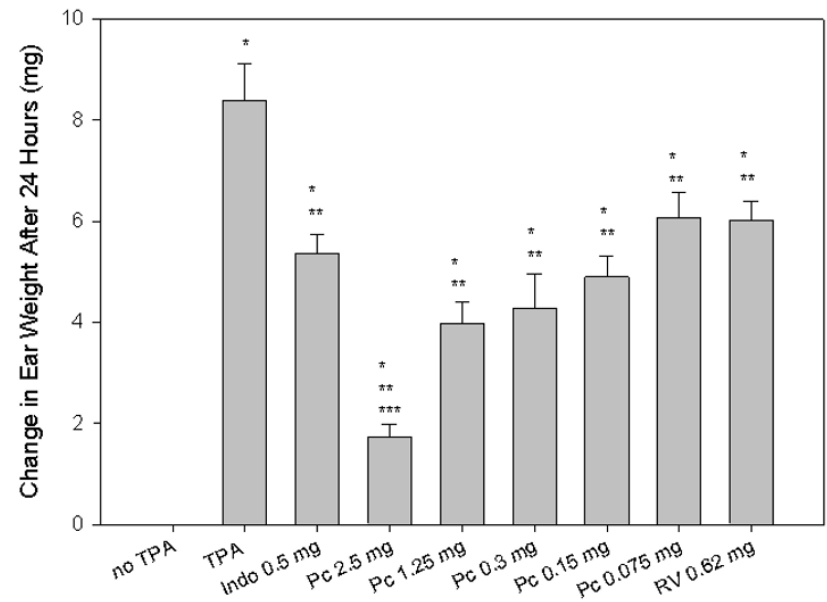

Figure 2

Change in ear thickness 4 and $24 \mathrm{~h}$ after TPA application. Ear thickness was measured with a digital micrometer 4 and $24 \mathrm{~h}$ after application of $2 \mu \mathrm{g}$ TPA. Abbreviations include Indo (indomethacin), PCE (Polygonum cuspidatum extract), and RV (resveratrol). Results represent means \pm SEM. ${ }^{*} \mathrm{P} \leq$ 0.05 compared to no TPA, ${ }^{* *} \mathrm{p} \leq 0.05$ compared to TPA control, $* * * \mathrm{p} \leq 0.05$ compared to indomethacin (Indo).

reduction). Resveratrol (0.62 $\mathrm{mg}$ ) produced an effect similar to indomethacin, and reduced the change in ear thickness to $6.02 \pm 0.38 \mathrm{mg}$.

\section{Myeloperoxidase activity}

Myeloperoxidase activity was measured in the ear punch biopsies taken $24 \mathrm{~h}$ after TPA administration as an index of neutrophil infiltration (Figure 3). Biopsies from ears treated with indomethacin at $0.5 \mathrm{mg} /$ ear and PCE at 1.25 and $2.5 \mathrm{mg} /$ ear doses had significantly reduced MPO activity. The higher PCE dose $(2.5 \mathrm{mg} /$ ear $)$ decreased MPO to $18 \%$ of the activity of the TPA-treated vehicle control group and was significantly more effective at decreasing MPO activity than indomethacin. Indomethacin $(0.5$ $\mathrm{mg} /$ ear) and PCE (1.25 mg/ear) inhibited MPO to the same extent at $53 \%$ and $45 \%$, respectively.

\section{Discussion}

An early hallmark of skin irritation and local inflammation in the TPA model is thickening within 1-4 h due to increased vascular permeability, edema and swelling within the dermis [32]. Topical application of PCE significantly inhibited ear edema at $4 \mathrm{~h}$ and $24 \mathrm{~h}$ after TPA treatment. Secondarily, PMN leukocytes migrate to the dermis within about $24 \mathrm{~h}$ and may be estimated by the MPO assay. Both of these inflammatory processes were blocked by topical application of PCE in a dose-dependent manner. PCE at a dose of $2.5 \mathrm{mg} /$ ear reduced edema and inhibited leukocyte infiltration to a greater extent than indomethacin $(0.5 \mathrm{mg} /$ ear $)$. Indomethacin is a potent 


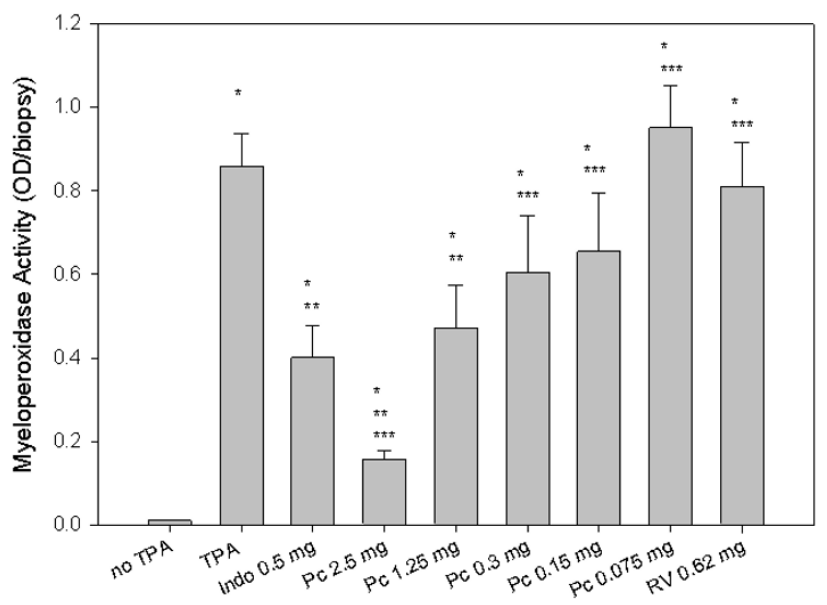

Figure 3

Myeloperoxidase activity. Myeloperoxidase activity (an index of neutrophil activation) was measured in ear punches $24 \mathrm{~h}$ after TPA administration. Abbreviations include Indo (indomethacin), PCE (Polygonum cuspidatum extract), and RV (resveratrol). Results represent means \pm SEM. ${ }^{*} p \leq 0.05$ compared to no TPA, ${ }^{* *} \mathrm{p} \leq 0.05$ compared to TPA control, $* * * p \leq 0.05$ compared to indomethacin.

non-steroidal, anti-inflammatory drug. It has an $\mathrm{LD}_{50}$ of $50 \mathrm{mg} / \mathrm{kg}$ in mice based on a 14 day mortality response [33]. This $\mathrm{LD}_{50}$ translates to $1.25 \mathrm{mg}$ indomethacin per 25 g mouse, just above the dose administered topically (1 $\mathrm{mg} / \mathrm{mouse}$ ). In contrast, no significant toxicity has been shown for PCE in this bioequivalence range. These data show that an ethanolic solution of PCE reduces inflammation to a similar extent as indomethacin or trans-resveratrol.

PCE is widely used in nutraceutical products because of consistently high concentration of resveratrol and its glucosides. Resveratrol derivatives in extracts of PC root include several glycosides $[1,34,35]$. In addition, PC contains emodin and a glycoside. However, Figure 1 shows that the ethanol-soluble fraction of the commercial concentrate used here was less complex than crude extracts of PC root $[2,34,35]$. The chromatogram agrees with the certificate of analysis of that PCE powder, 200:1, contains at least 50\% trans-resveratrol and less than 2\% emodin. In our tests, PCE was similar in activity to trans-resveratrol on a mass basis (Figures 2 and 3).

Our data are consistent with findings that trans-resveratrol and its derivatives have anti-inflammatory activity. For example, resveratrol and its glycosides inhibit human TNF- $\alpha$ and LPS-induced activation of NF- $\kappa$ B [36,37]. Resveratrol inhibits induced production of prostaglandin $\mathrm{E}_{2}$ release from human peripheral blood leukocytes [38]. In a model of early colonic inflammation in rats, resveratrol significantly decreases elevated plasma levels of prostaglandin $\mathrm{D}_{2}$ and the expression of COX-2 [39]. Resveratrol also inhibits the TPA-induced mouse dorsal skin inflammatory response by reducing NF- $\kappa \mathrm{B}$ and activator protein$1[40,41]$.

The TPA model of ear inflammation is useful for screening prospective topical anti-inflammatory compounds or botanical extracts that act at a variety of levels. In epidermal cell culture, TPA stimulates cell proliferation and increases the formation of leukotrienes and prostaglandins [42]. Phospholipase $A_{2}$ inhibitors have proven effective against both leukocyte infiltration and edema in the TPA model of ear inflammation [43]. Products of arachidonic acid metabolism such as $\mathrm{PGI}_{2}$ and $\mathrm{LTB}_{4}$ increase vascular permeability leading to edema during the inflammatory response [23], and compounds inhibiting COX and LOX enzymes have been shown to inhibit TPAinduced inflammation [23]. TPA applied topically to mouse ears promotes mast cell infiltration with release of mediators that increase vascular permeability and promote neutrophil influx [22].

In addition to 50\% resveratrol, PCE extract contains compounds such as quercetin and emodin that have antiinflammatory activities. It is known that additive and syngergistic interactions of polyphenols occur in vitro $[44,45]$. For example, in human leukemia cells, ellagic acid and quercetin interact synergistically with resveratrol to induce apotosis and cell cycle arrest [18]. Emodin, an anthraquinone, is present in PC rhizomes at concentrations similar to resveratrol and piceid [2]. However, the emodin content in PCE is reduced during processing to achieve a final content of $\leq 20 \mathrm{mg} / \mathrm{g}$. This is important because PCE is a constituent in products that are ingested, and it is desirable to reduce the risk of unpleasant gastrointestinal side effects in humans [46]. Emodin is a phytoestrogen with anti-viral and anti-inflammatory actions [47]. It inhibits NF- $\kappa \mathrm{B}$ activation and I $\mathrm{B}$ degradation, and decreases gene expression of cell surface adhesion proteins in vascular endothelial cells [6]. Emodin also effectively inhibits gene expression for TNF- $\alpha$, iNOS, and IL-10 in RAW 264.7 macrophages by activating I $\kappa$ B [48]. Thus, even though emodin levels in PCE have been reduced from levels in crude extracts, it may contribute to the topical anti-inflammatory activity of PCE. The present work shows that PCE and trans-resveratrol are anti-inflammatory in the mouse ear model, and that PCE could provide anti-inflammatory properties to cosmeceutical and dermatological products.

\section{Abbreviations used}

TPA: 12-O-tetradecanoylphorbol-13-acetate, PMN: Polymorphonuclear, MPO: Myeloperoxidase, TNF- $\alpha$ : Tumor Necrosis Factor - alpha, IL-6, -1 $\beta$, -8: Interleukin-6, -1 $\beta$, - 
8, COX: Cyclooxygenase, LOX: Lipoxygenase, Indo: Indomethacin, PC: Polygonum cuspidatum, PCE: Polygonum cuspidatum extract in 50\% ethanol

\section{Competing interests}

The author(s) declare that they have no competing interests.

\section{Authors' contributions}

The study was conceived by DKH and LW. EB conducted the study as part of her doctoral research under the direction of PG, DKH and JLH. EB and JLH prepared the figures and manuscript, which was reviewed and approved by each of the coauthors.

\section{Acknowledgements}

The authors thank Ms. Linda Duncan for her technical assistance and help with animal care and Emily Kelso for obtaining the chromatogram. We thank Dr. Ron Pegg, Dept. of Food Science and Technology, University of Georgia, for analyzing the constituents of the extract used in this study.

\section{References}

I. Vastano BC, Chen Y, Zhu N, Ho CT, Zhou Z, Rosen RT: Isolation and identification of stilbenes in two varieties of Polygonum cuspidatum. J Agric Food Chem 2000, 48(2):253-256.

2. Chu X, Sun A, Liu R: Preparative isolation and purification of five compounds from the Chinese medicinal herb Polygonum cuspidatum Sieb. et Zucc by high-speed counter-current chromatography. Journal of chromatography 2005, 1097(I2):33-39.

3. Editor Committee of Jiangsu New Medical College: Encyclopedia of Traditional Chinese Medicine. Shanghai, Shanghai Science and Technology Press; 200I: I 329.

4. Hsu CY, Chan YP, Chang J: Antioxidant activity of extract from Polygonum cuspidatum. Biological research 2007, 40(I): |3-2|.

5. Masaki H, Sakaki S, Atsumi T, Sakurai H: Active-oxygen scavenging activity of plant extracts. Biological \& pharmaceutical bulletin 1995, 18(1):162-166.

6. Kumar A, Dhawan S, Aggarwal BB: Emodin (3-methyl-1,6,8-trihydroxyanthraquinone) inhibits TNF-induced NF-kappaB activation, IkappaB degradation, and expression of cell surface adhesion proteins in human vascular endothelial cells. Oncogene 1998, 17(7):913-918.

7. Manna SK, Mukhopadhyay A, Aggarwal BB: Resveratrol suppresses TNF-induced activation of nuclear transcription factors NFkappa B, activator protein-I, and apoptosis: potential role of reactive oxygen intermediates and lipid peroxidation. J Immunol 2000, I 64(I 2):6509-65I9.

8. Zhao KS, Jin C, Huang X, Liu J, Yan WS, Huang Q, Kan W: The mechanism of Polydatin in shock treatment. Clinical hemorheology and microcirculation 2003, 29(3-4):2 I I-2I7.

9. Donnelly LE, Newton R, Kennedy GE, Fenwick PS, Leung RH, Ito K, Russell RE, Barnes PJ: Anti-inflammatory effects of resveratrol in lung epithelial cells: molecular mechanisms. Am J Physiol Lung Cell Mol Physiol 2004, 287(4):L774-83.

10. Pinto MC, Garcia-Barrado JA, Macias P: Resveratrol is a potent inhibitor of the dioxygenase activity of lipoxygenase. Journal of agricultural and food chemistry 1999, 47( ( 2):4842-4846.

11. Carluccio MA, Siculella L, Ancora MA, Massaro M, Scoditti E, Storelli $C$, Visioli F, Distante A, De Caterina R: Olive oil and red wine antioxidant polyphenols inhibit endothelial activation: antiatherogenic properties of Mediterranean diet phytochemicals. Arterioscler Thromb Vasc Biol 2003, 23(4):622-629.

12. Ferrero ME, Bertelli AA, Pellegatta F, Fulgenzi A, Corsi MM, Bertelli A: Phytoalexin resveratrol (3-4'-5-trihydroxystilbene) modulates granulocyte and monocyte endothelial adhesion. Transplant Proc 1998, 30(8):4191-4193.

13. Banerjee S, Bueso-Ramos C, Aggarwal BB: Suppression of 7,12dimethylbenz(a)anthracene-induced mammary carcinogen- esis in rats by resveratrol: role of nuclear factor-kappaB, cyclooxygenase 2, and matrix metalloprotease 9. Cancer Res 2002, 62(17):4945-4954.

14. Schneider Y, Duranton B, Gosse F, Schleiffer R, Seiler N, Raul F: Resveratrol inhibits intestinal tumorigenesis and modulates host-defense-related gene expression in an animal model of human familial adenomatous polyposis. Nutr Cancer 200I, 39(1): 102-107.

15. Roldan A, Palacios V, Caro I, Perez L: Resveratrol content of Palomino fino grapes: influence of vintage and fungal infection. J Agric Food Chem 2003, 5 I (5): I 464-I 468.

16. Pastrana-Bonilla E, Akoh CC, Sellappan S, Krewer G: Phenolic content and antioxidant capacity of muscadine grapes. J Agric Food Chem 2003, 5 I ( I 8):5497-5503.

17. Yilmaz Y, Toledo RT: Major flavonoids in grape seeds and skins: antioxidant capacity of catechin, epicatechin, and gallic acid. J Agric Food Chem 2004, 52(2):255-260.

18. Mertens-Talcott SU, Percival SS: Ellagic acid and quercetin interact synergistically with resveratrol in the induction of apoptosis and cause transient cell cycle arrest in human leukemia cells. Cancer Letters 2005, 218(2): |4I-I5I.

19. Conney AH, Lysz T, Ferraro T, Abidi TF, Manchand PS, Laskin JD, Huang MT: Inhibitory effect of curcumin and some related dietary compounds on tumor promotion and arachidonic acid metabolism in mouse skin. Advances in enzyme regulation | 991, 3 I:385-396.

20. Gabor M: Models of acute inflammation in the ear. Methods in molecular biology (Clifton, NJ 2003, 225: I29-I37.

21. Griffiths RJ, Wood BE, Li S, Blackham A: Pharmacological modification of 12-0-tetradecanoylphorbol-13-acetate induced inflammation and epidermal cell proliferation in mouse skin. Agents Actions 1988, 25(3-4):344-35I.

22. Rao TS, Currie JL, Shaffer AF, Isakson PC: Comparative evaluation of arachidonic acid (AA)- and tetradecanoylphorbol acetate (TPA)-induced dermal inflammation. Inflammation 1993, I7(6):723-741.

23. Carlson RP, O'Neill-Davis L, Chang J, Lewis AJ: Modulation of mouse ear edema by cyclooxygenase and lipoxygenase inhibitors and other pharmacologic agents. Agents Actions 1985, I7(2):197-204.

24. Chung WY, Jung YJ, Surh YJ, Lee SS, Park KK: Antioxidative and antitumor promoting effects of [6]-paradol and its homologs. Mutat Res 200I, 496(I-2): 199-206.

25. Hara H, Sukamoto T, Ohtaka H, Abe K, Tatumi $Y$, Saito $Y$, Suzuki A, Tsukamoto G: Effects of baicalein and alpha-tocopherol on lipid peroxidation, free radical scavenging activity and I 2-Otetradecanoylphorbol acetate-induced ear edema. Eur J Pharmacol I992, 22 I(2-3): 193-198.

26. Cui XY, Kim JH, Zhao X, Chen BQ, Lee BC, Pyo HB, Yun YP, Zhang $\mathrm{YH}$ : Antioxidative and acute anti-inflammatory effects of Campsis grandiflora flower. J Ethnopharmacol 2005.

27. Slinkard K, Singleton VL: Total phenolic analysis: automation and comparison with manual methods. Am J Enol Vitic 1977, 28:49-55.

28. Benzie I, Strain J: The ferric reducing ability of plasma (FRAP) as a measure of "antioxidant power": the FRAP assay. . Anal Biochem 1996, 239:70-76.

29. Dell RB, Holleran S, Ramakrishnan R: Sample size determination. ILAR journal / National Research Council, Institute of Laboratory Animal Resources 2002, 43(4):207-213.

30. Suzuki K, Ota H, Sasagawa S, Sakatani T, Fujikura T: Assay method for myeloperoxidase in human polymorphonuclear leukocytes. Anal Biochem 1983, 132(2):345-352.

31. Young JM, Spires DA, Bedord C], Wagner B, Ballaron SJ, De Young LM: The mouse ear inflammatory response to topical arachidonic acid. J Invest Dermatol I 984, 82(4):367-37I.

32. De Vry CG, Valdez M, Lazarov M, Muhr E, Buelow R, Fong T, lyer S: Topical application of a novel immunomodulatory peptide, RDP58, reduces skin inflammation in the phorbol esterinduced dermatitis model. J Invest Dermatol 2005, I 25(3):473-48I.

33. Barnhart ER: Monography. Indomethacin. 43rd Ed. Physician's Desk Reference. In 43rd Ed Physician's Desk Reference Edited by: Barnhart ER. New Jersey, Medical Economics Co.; 1 1989:1345-I 350.

34. Matsuda H, Shimoda H, Morikawa T, Yoshikawa M: Phytoestrogens from the roots of Polygonum cuspidatum (Polygonaceae): 
structure-requirement of hydroxyanthraquinones for estrogenic activity. Bioorg Med Chem Lett 200I, I I (14): I839-I842.

35. Chu $Q$, Peng $Y, Y e$ J: Determination of Active Ingredients of Polygonum cuspidatum Sied. et Zucc. by Capillary Electrophoresis with Electrochemical Detection. Electroanalysis 2004, 16(17): 1434-1438.

36. Heynekamp JJ, Weber WM, Hunsaker LA, Gonzales AM, Orlando RA, Deck LM, Jagt DL: Substituted trans-stilbenes, including analogues of the natural product resveratrol, inhibit the human tumor necrosis factor alpha-induced activation of transcription factor nuclear factor KappaB. J Med Chem 2006, 49(24):7|82-7|89.

37. Ashikawa K, Majumdar S, Banerjee S, Bharti AC, Shishodia S, Aggarwal BB: Piceatannol inhibits TNF-induced NF-kappaB activation and NF-kappaB-mediated gene expression through suppression of IkappaBalpha kinase and p65 phosphorylation. J Immunol 2002, I69(I I ):6490-6497.

38. Richard N, Porath D, Radspieler A, Schwager J: Effects of resveratrol, piceatannol, tri-acetoxystilbene, and genistein on the inflammatory response of human peripheral blood leukocytes. Mol Nutr Food Res 2005, 49(5):43I-442.

39. Martin AR, Villegas I, La Casa C, de la Lastra CA: Resveratrol, a polyphenol found in grapes, suppresses oxidative damage and stimulates apoptosis during early colonic inflammation in rats. Biochem Pharmacol 2004, 67(7): 1399-1410.

40. Kundu JK, Shin YK, Kim SH, Surh YJ: Resveratrol inhibits phorbol ester-induced expression of COX-2 and activation of NFkappaB in mouse skin by blocking IkappaB kinase activity. Carcinogenesis 2006, 27(7): | 465-|474.

4I. Kundu JK, Shin YK, Surh YJ: Resveratrol modulates phorbol ester-induced pro-inflammatory signal transduction pathways in mouse skin in vivo: NF-kappaB and AP-I as prime targets. Biochem Pharmacol 2006, 72(II):I506-15I5.

42. Fischer SM, Baldwin JK, Jasheway DW, Patrick KE, Cameron GS: Phorbol ester induction of 8-lipoxygenase in inbred SENCAR (SSIN) but not C57BL/6J mice correlated with hyperplasia, edema, and oxidant generation but not ornithine decarboxylase induction. Cancer Res 1988, 48(3):658-664.

43. Tramposch KM, Steiner SA, Stanley PL, Nettleton DO, Franson RC, Lewin AH, Carroll Fl: Novel inhibitor of phospholipase A2 with topical anti-inflammatory activity. Biochem Biophys Res Commun 1992, I 89(I):272-279.

44. Pignatelli P, Di Santo S, Buchetti B, Sanguigni V, Brunelli A, Violi F: Polyphenols enhance platelet nitric oxide by inhibiting protein kinase C-dependent NADPH oxidase activation. Effect on platelet recruitment. Atherosclerosis Supplements 2006, 7(3):439-439.

45. Mertens-Talcott SU, Talcott ST, Percival SS: Low concentrations of quercetin and ellagic acid synergistically influence proliferation, cytotoxicity and apoptosis in MOLT-4 human leukemia cells. Journal of Nutrition 2003, I33(8):2669-2674.

46. Srinivas G, Babykutty S, Sathiadevan PP, Srinivas P: Molecular mechanism of emodin action: Transition from laxative ingredient to an antitumor agent. Med Res Rev 2006.

47. Zhang C, Zhang X, Zhang $Y, X u$ Q, Xiao H, Liang X: Analysis of estrogenic compounds in Polygonum cuspidatum by bioassay and high performance liquid chromatography. J Ethnopharmacol 2006, I05( I-2):223-228.

48. Li HL, Chen HL, Li H, Zhang KL, Chen XY, Wang XW, Kong QY, Liu $\mathrm{J}$ : Regulatory effects of emodin on NF-kappaB activation and inflammatory cytokine expression in RAW 264.7 macrophages. Int J Mol Med 2005, I 6(I):4I-47.

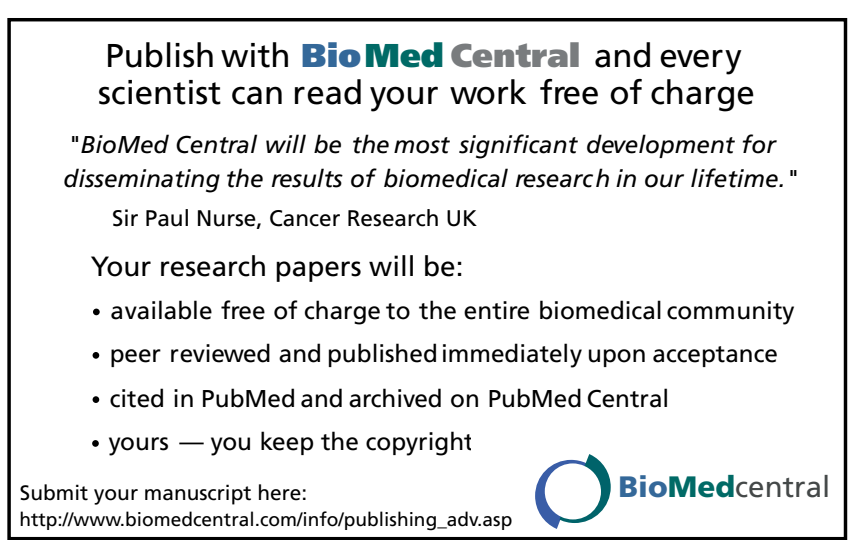

